\title{
The relationship between risk control imperative and perceived causation: the case of product counterfeiting in China
}

B Ding, School of Management, University of Science and Technology of China, Hefei, 230026, China

Email dingbin@ustc.edu.cn. Telephone (+86) 5513600619

M Stevenson, Department of Management Science, Lancaster University, Lancaster, LA1 4YX, UK. Email m.stevenson@lancaster.ac.uk. Telephone (+44) 1524593847

J S Busby, Department of Management Science, Lancaster University, Lancaster, LA1 4YX, UK. Email j.s.busby@lancaster.ac.uk. Telephone (+44) 1524594777

\section{Abstract}

The counterfeiting of safety critical products such as pharmaceuticals is a significant risk to public safety, but the literature suggests that much of the causation of counterfeiting is endogenous: the decisions of legitimate producers and consumers facilitate or incentivise the manufacture of counterfeits. This study examined what effect the perceived causation of counterfeiting risk (both the causes of counterfeiting, and the consequences caused by counterfeiting) had on the risk control imperative: the belief that more resources should be allocated to controlling this risk. This involved a questionnaire survey of individuals in China, asking them to respond to the risks arising from the counterfeiting of specific safety-critical product types. The study found that, although some causes of counterfeiting were emphasised much more strongly than others (notably the failure of the authorities, profiteering among legitimate producers and the presence of criminal organizations), the less emphasised causes were still judged as being relevant. The study found that the association between the risk control imperative and both the perceived scale of risk and its causal origins varied across 
different product types. In one case, the scale of risk was virtually unrelated to control imperative, but in all cases at least one of the causal factors, and at least one of the consequential factors, explained variation in control imperative. A qualitative comparative analysis also indicated specifically that control imperative was lower if an actor who was strongly implicated in the cause of the risks was also a bearer of the risks.

Keywords: Product counterfeiting, public safety, perception of causation, control imperative

\section{Acknowledgements}

Many thanks are due to the reviewers of a previous version of this article for their incisive comments and advice.

\section{INTRODUCTION}

Product counterfeiting has become a significant risk to public safety. Counterfeits have been found in markets ranging from microelectronic devices (recently, for example, Villasenor and Tehranipoor, 2013) to pharmaceuticals (recently, for example, Gillette, 2013). Counterfeiting essentially involves passing off products as though they came from some other more reputable producer, generally infringing trademarks (WTO, 2013), and producing economic losses for genuine producers. But counterfeit goods are also often poorly made, from substandard materials, which in the case of safety critical goods can have fatal consequences: a recently reported example is of cellphone chargers allegedly causing electrocution (Merz, 2013). Counterfeit shear bolts and sleeves were implicated in an air disaster some time ago (IACC, 2005). And news reports have claimed that fifteen per cent of pharmaceuticals imported into the USA are counterfeits (Lister, 2006).

As we argue below, the causes of counterfeiting at least partially arise from the actions of legitimate actors. Counterfeiting is not simply a threat from external agents, but a threat that is influenced by the 
behaviours of both producers and consumers (for example Cordell et al., 1996; Mackenzie, 2010). We suggest that this makes it important to investigate the perception of counterfeiting risk, the perception of its causes, and the relationship between the two. In particular, it is important to understand how strong is the perceived imperative to control this risk at a societal level, and how far this imperative is explained by the perceived causation. This appears not to have been studied hitherto, and constitutes the research gap we address in this paper. We do this by describing a survey of individuals in China. Chinese consumers in particular are claimed to be habituated to consuming counterfeits (Minagawa et al 2007). And China is seen as being culturally and institutionally predisposed to producing counterfeits (Ming \& Xing, 2000; Jiang et al., 2007; Cai et al., 2010). The study attempted to analyse how individuals' perception of the causes and consequences of counterfeiting of safety critical goods explained their judgment of how important it was to control the risks of counterfeiting. We looked at how judgments of causation compared with the perceived size of the risk in contributing to the risk control imperative. And we examined whether the explanation of control imperative remained constant across fundamentally different kinds of safety critical product.

In the remainder of the article we first survey the literature on counterfeiting, summarising the causes and consequences of counterfeiting risks, and suggesting a model of causation that we can use to explore the perception of causation. We then describe the methods used in the survey, give the results, discuss the inferences that can be drawn from these, and present a conclusion. The intended contribution is to explore the perception of an important risk in contemporary society, and to explore the role of causal judgments in forming this perception.

\section{LITERATURE}

In this section we briefly review literature on product counterfeiting generally, and then briefly discuss work on the perception of causation within the general risk perception field. For the sake of convenience we have divided the counterfeiting review between the causes and the consequences of 
counterfeiting.

\subsection{Factors contributing to counterfeiting activity}

There is some literature on theoretical models of product counterfeiting (for example Grossman and Shapiro, 1988a; Grossman and Shapiro, 1988b; Feinberg and Rousslang, 1990) but the most relevant literature to an analysis of risk perceptions is that making empirical observations. A wide range of factors are said to facilitate or encourage counterfeiting. Some of these are essentially cultural, geographical, and economic. For example, certain cultures inherently lack strong norms protecting trademarks and other intellectual property (Aryanto, 2003, citing Carver, 1996). In such cultures it is 'selfish and antisocial for the individual to insist on special compensation for [their] contribution' (Green and Smith, 2002). There is often an associated lack of institutional capacity to regulate and act against counterfeiting (Aryanto, 2003), especially in developing countries (Green and Smith, 2002), and this is sometimes linked to corruption (Santos and Ribeiro, 2007). In the case of counterfeit pharmaceuticals there has been inadequate legislation and enforcement, poor liaison among the relevant authorities, a lack of knowledge about counterfeits among health workers and the public, and the sale of medicines by untrained vendors, without prescription (Newton et al., 2006). Regulatory deficits are by no means confined to developing countries. Vagg and Harris's (2000) UK study points to the inadequacy of anti-counterfeiting activity in trading standards authorities, budget restrictions that limit counterfeiting prosecutions, and the fragmentation of anti-counterfeiting effort over the various enforcement agencies.

Disparities in levels of economic development also encourage copying in less developed regions. Aryanto (2003) claims that lags in technology and a lack of spending on research and development has led to counterfeiting. Counterfeiting can be seen as a source of employment (Green and Smith, 2002) and combating it has a low priority where there are significant economic problems (Yar, 2008). Trade barriers also have a significant effect. Their removal and the associated increase in cross-border flows, together with limited customs inspections (Aryanto, 2003; Yar, 2005), facilitates the trafficking 
of counterfeits. Yet counterfeiting can also be facilitated by import barriers that sustain local monopolies and encourage the copying of foreign brands (Shen et al., 2010). And the presence of criminal organizations which exploit the opportunities offered by counterfeiting to fund other criminal activity and launder money (Rutter and Bryce, 2008 ) appears to be a significant factor. Mackenzie (2010), for example, refers to 'the creation and maintenance of highly profitable organized crime activity in international markets for fake goods’.

Some of the causes of counterfeiting are claimed to be technological in nature. In particular, the technologies of replication like desktop publishing and photographic-quality printing (Yar, 2005) makes it increasingly cheap and straightforward to copy packaging and sometimes the good itself (Aryanto, 2003). Whereas formerly counterfeiters and forgers had to be highly skilled craftsmen, technology spreads the capacity for counterfeiting far more widely (Chaudhry and Walsh, 1996). Newton et al. (2006) report that even complex holograms are copied 'with such detail that it is impossible to detect counterfeits with the naked eye'. Unsurprisingly, the technology of the Internet has also been implicated. The Internet has been described as a 'nest for counterfeiting' (Juillet and Vlasto, 2005) for the fairly obvious reasons that it lacks borders and their associated controls. Mavlanova and Benbunan-Fich (2010) make the similarly obvious points that counterfeiters can trade on the Internet without prior consumer inspection, and use presentational devices to signal their apparent trustworthiness. Technologies of various kinds also provide a promising means of deterring or impeding counterfeiting, but the experience is that technological solutions are costly, inflating product prices and further increasing the price difference between legitimate and counterfeit products. And they may provide only temporary protection before counterfeiters find ways of circumventing them (Yar, 2008).

Another set of contributory factors involves consumer demand (Veloutsou and Bian, 2008). Consumers sometimes seem to have double standards, expecting businesses to have higher standards than themselves (Chan et al.., 1998). They are said to develop coping strategies to reduce the dissonance that might accompany the knowing consumption of counterfeits (Eisend and Schuchert- 
Güler, 2006). For example, they can devalue the importance of a counterfeit purchase, find ways of increasing the value of their choice, or devalue the legitimate product that they rejected. It has also been claimed that some consumer populations have attitudes that de-emphasize lawfulness and thus attach little stigma to the procurement of counterfeits (Cordell et al., 1996). Some have attitudes that are hostile to business corporations, which may only be worsened by the way in which such corporations defend their intellectual property (Mandhachitara et al., 2000; Tom, 1998). And some simply seem to have got into the habit of consuming counterfeits. Minagawa et al (2007) claim that 'Chinese consumers have become so accustomed to cheap, pirated goods that they are unwilling to pay full prices for the real thing.'

A further set of factors implicates legitimate producers. First, branding and advertising lead to goods having a fashion value over and above their use value, creating desires that may be satisfied just as well with fake goods as original ones (Mackenzie, 2010). Promotion combined with high prices not only creates incentives for counterfeiting, but also creates a market among consumers unable to afford the legitimate products. Second, legitimate producers can be perceived as profiteering, charging prices for branded products that may be seen by both potential counterfeiters and consumers as exorbitant (Green and Smith, 2002), and exercising what is perceived as monopolistic control over their authorized supply chains (Yar, 2005). Third, market segmentation and selling products at different prices in different countries produces 'gray' or parallel markets that facilitate infiltration by counterfeits. Segmentation creates strong incentives for counterfeiters to sell into higher-priced segments (Minagawa et al., 2007), and also means that counterfeits, disguised as parallel imports, become harder for the authorities to detect (Vagg and Harris, 2000). Fourth, outsourcing production in the pursuit of the lowest manufacturing costs creates opportunities for counterfeiting because designs, know-how and infrastructure are transferred to local producers (Mackenzie, 2010; Tom et al., 1998; Minagawa et al., 2007). Minagawa et al. (2007) argue that, even in the face of increased counterfeiting, firms have continued to outsource to developing countries where counterfeiting is a known problem. The licensing of technology is similarly seen as creating a vulnerability to reverse engineering and passing-off (Aryanto, 2003). Fifth, producers' decisions to cease production of goods 
that are still in demand presents a significant opportunity for counterfeiters. For example, Guide et al. (2003) argue that aircraft parts may have a functional life of less than five years, and acquiring a replacement may have a lead time in excess of two years, creating an obvious market opportunity for counterfeiters. Sixth, Newton et al. (2006) refer to the secrecy practiced by some manufacturers and governments about both the general scale of the problem and specific cases of counterfeiting. Some firms are said to be unwilling or unable to reply to requests for the authentication of products seized by the authorities suspecting they are counterfeits (Vagg and Harris, 2000).

The support offered for all these claims varies, and specific causes are likely to vary between contexts. But the literature points to how wide-ranging the causes of product counterfeiting are likely to be. It is also noteworthy how much attention the literature gives to the endogenous factors. As Trott and Hoecht (2007) claim, it is sometimes a firm's own strategies and lack of risk management that are responsible for the scale of the counterfeiting they face. And, as Qian's (2008) economic modeling recognizes, the entry of counterfeits cannot be counted as exogenous when it is influenced by the markup and quality levels that the firm sets. Even cultural and geographical influences become relevant endogenously when it is the choice of firms to distribute products into regions with cultures that encourage counterfeiting, and it is the choice of firms to outsource to, license to, or procure from those regions.

\section{2 Effects of counterfeiting activity}

In terms of the effects of counterfeiting, there are multiple problems for legitimate firms, mostly economic. They are likely to experience losses in immediate sales, losses in goodwill if poor quality is attributed to the genuine manufacturer (Dixon and Greenhalgh, 2002), and losses in brand equity if consumers realize that part of the available stock of a brand is counterfeit (Green and Smith, 2002, citing Wilke 1999). Consumers suffer a corresponding welfare loss if the status of a label declines (Grossman and Shapiro, 1988b). It is also quite likely that there will be price falls as expectations of quality are diminished (Qian, 2008). Considerable resources are consumed in acting against 
counterfeiters, for example by legal enforcement of trademark rights (Dixon and Greenhalgh, 2002). And there are broader consequences for the economies in which counterfeits are both made and sold: falls in tax revenues, job losses, reductions in innovation, the costs of the authorities acting against counterfeits in target countries, and the loss of foreign direct investment, foreign exchange earnings and tax revenues in the countries where counterfeiting takes place (Dixon and Greenhalgh, 2002).

The consequences are not just economic, however. Two in particular are discussed in the literature. The first is the extensive risks to personal safety (Forzley, 2003, Mackenzie, 2010), obviously in connection with products like pharmaceuticals and aircraft components (Green and Smith, 2002), but commodity electrical goods like battery chargers have also been involved in fatalities that have made the national press. Developing an objective account of the hazards of counterfeits has been difficult since most safety-related databases do not code for counterfeiting (Forzley, 2003). But counterfeit pharmaceuticals in particular pose severe risks to health (Newton et al., 2006). They may contain too little or none of the supposed active ingredient, and may contain placebos or even toxins, so causing serious illness, producing new side-effects or failing to provide the anticipated cure. The suspicion they engender may deter the purchase of the genuine product, they may mislead the medical fraternity about the efficacy of the original product, and ultimately may lead to the withdrawal of the genuine product (Bosworth, 2006; Newton et al., 2006). Counterfeit safety-critical automotive components are gaining a similar notoriety. Yar (2005) catalogues cases where counterfeit brake pads, hoods, oil filters and fenders are made from highly sub-standard materials - like compressed grass. In general, legitimate producers endeavor to avoid producing sub-standard products since their reputations suffer, but counterfeiters do not experience the same constraint. The other main non-economic consequence has been the sustaining and enabling of criminal activity. Under the causes of counterfeiting we suggested that the presence of criminal organizations facilitates counterfeiting, citing Mackenzie (2010) and Rutter and Bryce (2008). But equally the practice of counterfeiting provides a means for money laundering and a source of funds for other criminal activity, including terrorism. Counterfeiting is not only a criminal activity in its own right but also sustains other kinds of criminality. 
Although the general treatment of counterfeiting emphasizes its damaging effects, there do sometimes appear to be favorable effects for certain groups other than counterfeiters. It has been argued that, even for the legitimate producer, counterfeiting can help build brand awareness, providing 'bandwagon' and network effects (Eisend and Schuchert-Güler, 2006; Shultz and Saporito, 1996; Staake et al., 2009). Meanwhile, it may give a population access to goods that it could not otherwise afford (Green and Smith, 2002). The diffusion of new software, in particular, is said to be facilitated by the proliferation of counterfeits (Green and Smith, 2002), locking in users to that software and thereby presenting a barrier to entry for legitimate competitors (Staake et al., 2009). Trott and Hoecht (2007) argued that imitation is an essential part of the innovation. Such claims about the beneficial consequences of counterfeiting are likely to be controversial, but the important point is that there may well be a perception that certain legitimate actors sometimes benefit from it.

Figure 1 summarizes the claims made in the literature about the causes and consequences of counterfeiting. The wide range of factors indicated here raises a number of questions, such as which causes and consequences tend to be most strongly emphasized by risk perceivers, how the factors are correlated in their judgments, and how this varies with different products. And, perhaps most importantly, there is a question about how judgments of the causes and consequences of counterfeiting risks, especially the risks of counterfeited safety-critical goods, influence the acceptability of those risks and the imperative to control them.

Figure 1 about here

\subsection{Risk perception and causation}

How a society perceives the causation of risks arising from phenomena such as counterfeiting matters for several reasons. First, we know from Freudenberg (2003) that the perception of an organization's 'recreancy', or a failure to discharge its responsibilities, is one of the most important factors 
contributing to risk amplification. If producers are seen as a significant cause of counterfeiting, people are likely to exaggerate the risks of counterfeiting and desist from consumption - or exert political pressure for greater risk controls by the state. Second, we know from Wolff (2006) that the significance of a risk is very often determined by what we think causes it, irrespective of its size. Causes which are regarded as immoral in some way - for example because they involve deliberate deception - lead the risks to be regarded as socially unacceptable. Third, our theories of what causes risk clearly influence what we do to control it (Busby and Duckett, 2012). If we regard the causes of counterfeiting as being, in part, to do with anonymous trading channels, we are less likely to use such channels to procure goods at risk of being counterfeited.

Most risk perception studies concentrate on the causation of perception rather than the perception of causation. The attributes used in the longstanding psychometric model are described as 'dimensions hypothesised to influence perceptions of actual or acceptable risk' (Fischhoff et al., 1978). Similarly, the more recent emphasis on the affective determinants of risk perception (Finucane et al., 2000; Slovic et al., 2004; Dohle et al., 2010) is about affect as a cause of perception rather than affective reactions to the perception of causes. However, there is some precedent for studying the perception of causation. Kuhar et al. (2009), for example, investigated the perception of naturally occurring health risks, and one of their primary concerns was causation - both what caused such risks and what health consequences they caused in turn. And, typically, some of the attributes in the traditional psychometric studies are about causation. For example 'voluntariness' (Fischhoff et al., 1978) is about whether risk bearers cause a risk through the choices they make. Later work includes attitudes like 'trust in governmental agencies’ (Siegrist et al., 2007) which at least indirectly involve the perceptions of other actors as being causal agents in some way.

Typically, risk perception studies are also comparative by intention: asking why (the same) people see risks in radically different contexts differently. This creates problems of knowing what is meant by a 'risk' when it is applied over different contexts. And, until subsequent studies (Marris et al., 1997; Langford et al., 1999; Bronfman et al., 2003; Siegrist et al., 2005), it was seen as glossing over the 
considerable variation among individuals perceiving the same risk. But there has also been a tradition of studies concerned primarily with specific risk domains, such as nanotechnology (Siegrist et al., 2007), flooding (Kellens et al., 2011), certain contamination events (Kuhar et al., 2009), terrorism (Lee and Lemyre, 2009; Caponecchia, 2012), and disease outbreaks (Prati et al., 2011). A study of perceptions around a specific risk - in our case product counterfeiting - again therefore has some precedent. It also belongs to an interesting class of risks. Unlike risks of accident and natural disaster, it involves intentionally wrongful action by a human agent. Even risks associated with technology, such as those of nanotechnology (for example Hornig Priest, 2012), are essentially accidents. However, unlike risks of terrorism (for example Lee and Lemyre, 2009), the intention behind counterfeiting risk is not primarily an intention to do harm. The counterfeiting of medication with clinically inactive substances is an intention to deceive but not to cause physical damage. Counterfeiting risks therefore occupy an interesting, and perhaps under-explored, middle ground between the commonly explored risks of accidental harm, on the one hand, and deliberate harm on the other.

Finally, central to the motivation for exploring risk perceptions has been the question of whether people find a risk acceptable. Policy makers want to know which risks are perceived to be unacceptable in order to know how to allocate risk-mitigating resources. But there are three main problems in analysing risk acceptance:

1. We accept or reject a technology, not just its risks. Most technologies are 'packages' of risks and benefits that cannot be easily separated (Slovic et al, 1982).

2. What makes a risk acceptable is not just the risk itself but the cost of mitigating it (Finkel, 2008). We accept some risks largely because they are so costly to reduce.

3. Counterfeiting is generally illegal and for many people clearly wrongful, and the notion that it can be acceptable may seem like a contradiction in terms.

Our approach is therefore not to ask about the acceptability of counterfeiting risk, but to ask whether people think that the counterfeiting risk should be subjected to greater control, and whether more resources should be allocated to this control. In other words we ask about 'risk control imperative' 
rather than risk acceptance. This judgment is a relative rather than absolute one, asking whether there is an imperative to control the risk, given all the other risks that need controlling and all the other uses to which resources could be put. And it allows the perceived costs of mitigation, and any perceived benefits, to enter into people's judgments. The aim of our study has therefore been to analyse how this control imperative is associated with the perception of how counterfeiting risks are caused, and what consequences they cause in turn.

\section{METHOD}

\subsection{Research question}

Our research question was how strongly does the perception of causation explain the risk control imperative in the case of product counterfeiting? This was addressed in three main stages:

1. An analysis of how a sample of individuals perceives the causation of the risks.

2. An analysis of the association between these causation perceptions and the control imperative expressed by the individuals.

3. An analysis of how this association varies between safety-critical counterfeited goods of three main types that differ in terms of their intrinsic risks

We use the model abstracted from the counterfeiting literature, in Figure 1, to organize our study and provide specific items for the empirical work.

\subsection{Questionnaire instrument}

The questionnaire contained a series of items based on the synthesised model shown in Figure 1. Four of the causes were excluded from the questionnaire (cost and transience of anti-counterfeiting technology, removal of trade barriers, market segmentation, and attitudes of lawlessness) on the basis that: 
1. individuals are in general unlikely to know about the costliness of anti-counterfeiting technology;

2. trade barrier removals mostly do not apply to counterfeits both produced and consumed within China;

3. market segmentation is similarly practiced across national borders so is not applicable to counterfeits circulating entirely within China;

4. general attitudes of lawlessness are unlikely to be experienced or reported in a survey of this kind.

These are conjectures, and it is possible that some of the variance in judgment not explained by the remaining items could have been explained by these deleted items. Respondents were asked to rate how strongly the set of possible causes explained counterfeiting risks, and how strongly the possible consequences were indicated. They were asked to rate the size of the risk they perceived, and to express a control imperative by stating how strongly they thought that 'more resources should be spent on managing the risks of this product being counterfeited'.

The questionnaire asked respondents to make these judgments for three different product types (alcoholic beverages, pharmaceuticals and automotive parts) that are known to have been counterfeited, and where counterfeits are known to have been sub-standard and clearly harmful to safety. All three types were safety critical in the sense that sub-standard products could result in obvious risks to individual safety or health. But they varied in that 1) one was explicitly intended to be health-improving (pharmaceuticals); 2) one had the potential for adverse health consequences even when products were not sub-standard (alcohol); 3) one was health-neutral in this sense (automotive parts). Having different product types enabled us to make an assessment of how constant individuals' causal attributions were, but also provided a stimulus to the respondents to think more widely and deeply about causation. To avoid fatigue just the three product types were incorporated in the design. The questionnaire is attached at an appendix, but was translated into Chinese before being administered by researchers in one author's institution. This translation was verified by an independent Chinese researcher in the other authors’ institution. 


\subsection{Data collection}

The questionnaire was administered in Chinese, on paper, to 450 individuals and responses were received from 358 (a response rate of 79.6\%). Of these, 337 were valid and complete. Respondents were recruited through the professional contacts of the author affiliated to the University of Science and Technology of China at Hefei. This included two management classes of part-time students, employees of 12 local firms, and a distribution of questionnaires to randomly-chosen visitors to the university campus. There was no substantial incentive, although all respondents except those in the 12 firms were given a souvenir valued at $3 \mathrm{CNY}$. All respondents claimed to be of Chinese nationality but this was a convenience sample and cannot be assumed to be somehow representative of the Hefei locale, of the province or the country. Demographic details were therefore also collected so that the sample could be characterised. Some 143 of the respondents were females and 194 males. Some 65 stated they were involved in work producing one of the products in question: 14 for alcohol beverages, 18 for pharmaceuticals and 33 for automotive parts. There is no a prior reason to expect a systematic bias as a result of this involvement: the involvement could produce either a heightened hostility to counterfeiters or a degree of sympathy. Figure 2 shows distributions of age, self-perceived wealth, employment, education, and locale for the respondent sample. This is intended to convey the nature of the sample, and demographic information was not used in the analysis.

Figure 2 about here

\subsection{Analysis procedure}

Principal component analysis was used to condense the causes into a small number of factors. Risk control imperative was then regressed against the condensed causes and the judged size of the risk, to find out how strongly causal beliefs predict control imperative in relation to perceived size. This helps us not only to find out if the judgment of causation plays a role in control imperative, but also to understand how important causation is relative to the size of a risk. If morality, trust (and other 
aspects of a situation that are related to how a threat comes about) are relevant to the acceptance of a risk, causation should be relatively important. If they are not, the size of the risk will presumably be a dominant consideration. Standard approaches generally also assess the role of perceived benefit (Fischhoff et al, 1978). Because our starting point is the model of Figure 1, all potential consequences within the basic causal structure were examined, and this includes different kinds of benefit. But it is important to remember that the context - of risks created by product counterfeiting - is different from the context of a legitimate product and service which are intended to be beneficial by design. The benefits, if there are any, from counterfeiting are relatively minor side-effects or by-products, as discussed earlier in the Literature Review (Eisend and Schuchert-Güler, 2006; Shultz and Saporito, 1996; Staake et al., 2009; Green and Smith, 2002; Trott and Hoecht, 2007). With legitimate products and services it is the risks that are typically side-effects or by-products. The analyses are carried out separately for the three product types so we can compare their factor structures and regression models.

The final part of the analysis involved a qualitative comparative analysis, assessing the basic idea that if causes were endogenous to some actor, and that actor was also a risk bearer, then risks would be more acceptable than otherwise. Using a this kind of analysis both 1) allows us to express the expected basis for how people make control imperative judgments in logical rather than statistical terms, and 2) allows us to examine what turns out to be a strongly asymmetrical relationship between control imperative and risk causation. This rationale naturally follows on from the results of the first analysis, so an explanation and justification for this procedure are incorporated in the Results section that follows.

\section{RESULTS}

\subsection{A description of causal judgments}


The ratings reported for the causes of counterfeiting are shown below in Figure 3, showing the mean plus and minus one standard deviation for all items for the three product types. The profile for all three product types was very similar. There was a strong tendency to ascribe counterfeiting to failures on the part of the authorities and profiteering by legitimate enterprise, as well as the presence of criminal organizations. And there was a de-emphasis of consumer attitudes and habit. Other causes ranked somewhere between these. But there was substantial variation among respondents, with the extreme values of the response interval being used for all items.

Figure 3 about here

In terms of the consequences, again the profiles for the three product types are similar as indicated in Figure 4.

Figure 4 about here

Clearly, the damage to individual and public health, plus the support of criminality, are the consequences most strongly perceived. The costs to genuine producers, both in terms of the reputational damage and the cash costs of dealing with counterfeits, also figure strongly. Beneficial consequences (such as greater consumer access, greater market exposure and lower genuine prices) are de-emphasised. Variation around the means tended to be proportionally greater for the lower-rated items, however, so there was more disagreement about lower-rated items than about higher-rated ones. It is clearly not everyone's perception that counterfeiting has beneficial consequences, but the means for even the lowest-rated items lie above the second point on the 5-point response interval (thus above 'not at all' in terms of effect). The notion that poorer consumers benefit is given more credence in the case of automotive parts than the other two product types, and that consumers suffer from lower product quality has more credence for pharmaceuticals and automotive parts than for alcohol. 


\subsection{The structure of causal judgments}

Tables 1 and 2 show the factors obtained from the principal components analyses separately for the different product types after varimax rotation. Factor labels are given at the base of the table, intended to capture the higher factor loadings shown in bold font. The first table (Table 1) concerns causation.

Table 1 about here

The factor structures for the different products are not radically different, but they are not identical. For alcohol, the first factor clearly implicates the role of the primary risk bearers (the consumers) in counterfeiting risks, also incorporating an item related to producers ('Genuine producers failing to meet to demand') that implicates consumers as well as producers. The second factor is perhaps less coherent, combining societal and technological causes with the damaging practices of producers. It suggests that technology facilitating counterfeiting (which could include both production and copying technology) is not specifically seen as an exogenous element. The third factor more clearly concerns the social environment. And the fourth combines the failure of the authorities with what might be regarded as the mistakes of producers. For pharmaceuticals, again the factor accounting for most variance clearly implicates consumers, the second factor implicates producers, and the third points to the social environment. The fourth factor this time is less coherent, combining technology and producers’ promotional practices. For automotive parts, the first factor again concerns consumer attitude and practice, the second the social and technological environment, and the third implicates

producers. For all three cases, failure by the authorities loads negatively and fairly substantially on the factor expressing consumer disposition, suggesting there is a pronounced opposition drawn between the authorities and consumers.

Table 2 shows factor structures for consequences, again separately for each product type. 
For alcohol, the factor structure clearly differentiates consumer and public loss from producer loss, and both kinds of loss from benefit to both consumers and producers. The only ambiguous feature is that producer price reduction is combined with benefits, suggesting that respondents identify the consumer benefits of price reduction more strongly than the producer losses. For pharmaceuticals, the structure is very similar, with consumer harm from product quality loss loading more heavily on consumer and public loss as might be expected. For automotive parts the structure was again similar, although now producer price reduction loads more heavily on producer loss than benefit.

\subsection{The association with control imperative}

The results of regressing the judgments of risk control imperative against the causal and consequential factors, and the size of the risk, are summarised in the following tables. Generally, the models show weak effects with very low adjusted $R^{2}$ values, but $p$-values that are statistically significant. Table 3 shows the regression models for causation.

Table 3 about here

The size of risk has a strongly statistically significant influence for pharmaceuticals and automotive parts, and more weakly for alcohol. But the picture for factors expressing judgments of causation is more ambiguous. For pharmaceuticals, all factors except producer-related causes have significant influences. For automotive parts, only causes related to society and technology are significant, and for alcohol only consumer-related causes have significance. This is commented on in the Discussion. As the data come from choices from a finite set of possible responses, and as the control imperative dependent variable is a single item, an ordinal logistic model is, in principle, more appropriate than a simple linear model. But applying such a model to the same data, both to the factor scores and subsequently also to interactions between them, appears to reveal no more than this analysis. 
Table 4 shows the models for control imperative against consequences and size of risk. As there was a similar set of principal components for each product type (with some differences in the items loading on them) these can be tabulated together, although it needs to be remembered that the independent variables listed on the left are defined slightly differently for each product type, as shown earlier in Table 2.

Table 4 about here

Again, although the models have statistical significance, values of adjusted $R^{2}$ are very low. In the case of alcohol the size of the risk has no obvious effect on control imperative, whereas all the consequential factors do; yet in the case of pharmaceuticals and automotive parts, the consumer and public loss is the only consequential factor with a statistically significant effect, and the size of the risk is significant.

\subsection{A qualitative comparative analysis}

A qualitative comparative analysis was then carried out broadly using the method suggested by Ragin (2009) to look at the relationship between control imperative judgments and the location of responsibility. One problem with the data is that the distribution of risk control imperative judgments is strongly skewed towards high ratings. This was not inevitable, given comments in the literature about the apparent normality of counterfeiting in China, but may reflect the fact that such comments are now several years old. So low control imperative turned out to be relatively unusual, and what is therefore of primary interest is what conditions are associated with this low control imperative. It was suggested earlier that a key aspect of causation in the counterfeiting context was endogeneity: the way in which the decisions of legitimate actors (not just the counterfeiters) contributed to counterfeiting risk. This suggests that we should test the idea that if actor $A$ is the one mainly at risk, finding low control imperative means that $A$ is the one mainly responsible for the cause of the risk. The regression 
models do not examine this notion, which we call 'risk bearer causation', since they were set up to compare separately the role of causes and consequences with the size of the risk in explaining control imperative ratings. Regression also essentially looks for a symmetric relationship where, for example, low control imperative is associated with high risk bearer causation, and high control imperative is associated with low risk bearer causation. We are suggesting that where there is low control imperative then there should be high risk bearer causation (the reason for low control imperative). But where there is high control imperative there may or may not be low risk bearer causation, since other reasons (probably moral) producing control imperative may dominate.

Following Ragin (2009) and similar studies, reviewed for example by Rihoux (2006), we can use a 'configurational' approach to follow more closely the reasoning of what inhibits control imperative. The basic intuition expressed in the previous paragraph, that lack of control imperative logically implies risk bearer causation, can be stated in basic propositional form as:

Control imperative $\supset$ Risk bearer causation

There are broadly two possibilities for the right-hand term, giving:

$\sim$ Control imperative $\supset$ (Consumer losses $\supset$ Consumer causes)

or:

$\sim$ Control imperative $\supset$ (Consumer causes $\supset$ Consumer losses)

The first says that whenever the consumer is at risk of some loss, they should also be a cause of the risk in order for there to be 'risk bearer causation'. On the other hand, the second says that whenever the consumer is judged to be a cause, they should be at risk of loss. The same possibilities apply to producers, their losses and their roles as causal agents, so we can use the data to explore the following models:

$\sim$ Control imperative $\supset$ ((Consumer losses $\supset$ Consumer causes) $\mathrm{V}$

(Producer losses $\supset$ Producer causes))

And:

$\sim$ Control imperative $\supset$ ((Consumer causes $\supset$ Consumer losses) $\vee$

(Producer causes $\supset$ Producer losses)) 
We investigate this by following Ragin's (2009) procedure of interpreting judgment levels (the respondent ratings) as membership values of fuzzy sets, and applying fuzzy set interpretations of Boolean operators. Because the factor structure of causes did not follow actors exactly, the original items are used to formulate a value for:

Consumer causes $\equiv$ Consumer willingness to consume counterfeits $\mathrm{V}$

Consumer hostility towards large businesses $\mathrm{V}$

Consumer buying counterfeits out of habit

Similarly:

Consumer losses $\equiv$ Consumers suffer poor health or injury $\mathrm{V}$

Consumers suffer loss of product quality $\mathrm{V}$

Public health deteriorates $\mathrm{V}$

Society suffers from funding of criminality

For producers:

Producer causes $\equiv$ Heavy product promotion $\mathrm{V}$

Making large profits $\mathrm{V}$

Authorizing others to make their products $\mathrm{V}$

Providing insufficient products to meet demand V

Hiding the fact of counterfeiting

And:

Producer losses $\equiv$ Reputation loss $\mathrm{V}$

Price reduction $\mathrm{V}$

Sales fall $\mathrm{V}$

Costs of counteracting counterfeits

Ratings on a response interval of 1 to 5 are converted linearly into a fuzzy membership function from 0 to 1.0. Conjunctions are found in fuzzy logic by taking a minimum and disjunctions by taking a maximum. The linear membership function is an assumption, and seems reasonable given the intuitiveness of linearity for subjects making their responses. But - as we have no evidence to support 
this - the results must be seen as being provisional. Kochen (1975) indicates that variation in reasoning style among individuals does affect the relevant membership function. And Ragin (2000, p. 167) cautions against simply assuming low and high ratings can be translated into low and high membership values. But he also (Ragin, 2000, p. 169) suggests taking respondent-given ratings as membership scores. And Yen and Langari (1999, p. 27), while listing a wide range of possible membership functions, recommend triangular or trapezoidal functions (corresponding to our linear relation between rating and membership) 'unless there is a good reason to do otherwise'. In the results below we assess their sensitivity to different assumptions about the relevant membership function.

Ragin's (2006) consistency index tests for the condition that some configuration implies some outcome. It is defined as

$$
\operatorname{Consistency}\left(X_{i}, Y_{i}\right)=\sum_{i}\left(\operatorname{minimum}\left(X_{i}, Y_{i}\right)\right) / \sum_{i}\left(X_{i}\right)
$$

where $X_{i}$ and $Y_{i}$ are specific configurations and outcomes. In our case we want to test whether inhibited control imperative implies risk bearer causation. So our $X_{i}$ are the control imperative judgments and our $Y_{i}$ are the strengths with which risk bearer causation holds. The index is high when the $X_{i}$ are consistently lower than the corresponding $Y_{i}$ or equal to them. This is indicated because the conditions which contradict the implication $X \supset Y$ are those in which there is a strong belief in $X$ but only a weak one in $Y$. Ragin (2006) also defines coverage as

$$
\text { Coverage }\left(X_{i}, Y_{i}\right)=\sum_{i}\left(\operatorname{minimum}\left(X_{i}, Y_{i}\right)\right) / \sum_{i}\left(Y_{i}\right)
$$

This is high only when risk bearer causation also implies inhibited control imperative, in other words when there are no other, more dominant factors that shape control imperative. There are two logical forms to test, (1) and (2) indicated above, for each of the three product types. Table 5 shows the results. 
The high consistency values show that the data is strongly consistent with our proposed models. But the low coverage values show that much of what explains the risk control imperative lies beyond the condition of risk bearer causation.

Finally, to give some idea of the sensitivity of these results to our assumption about a linear membership function, we re-calculated the consistency and coverage values for the third product assuming a relatively steep logistic membership function, $f(x)=1 /\left(1+\mathrm{e}^{-3(x-3)}\right)$, which maps ratings [1, $2,3,4,5]$ to approximately $[0.00,0.05,0.50 .0 .95,1.0]$ instead of $[0,0.25,0.5,0.75,1.0]$. This changes the consistency and coverage values shown in Table 5 from $(0.992,0.959)$ and $(0.200,0.220)$ to $(0.988,0.932)$ and $(0.13,0.13)$. The numerical results are thus different, but the qualitative conclusions are unchanged.

\section{DISCUSSION}

\subsection{Causal judgments}

Certain causes and certain consequences were given much greater credence than others. In particular, agency for counterfeiting risks was most strongly attributed to criminal organizations, profiteering producers and inept state authorities. Substantially less credence was given to cultural explanations, and very little to the behaviour and attitudes of consumers. Thus the picture is one in which individuals see causation as mostly arising from specific, organizational actors. But it is important to say that all causes and consequences received average responses greater than 'none at all'. Respondents, in aggregate, recognized that consumers played a finite, if small, role in the risks arising from counterfeits, and that there was a finite, if small, benefit to parts of legitimate society.

The factor structures tended to separate out causation according to the main agents - distinguishing causes attributable to consumers from those attributable to producers and those attributable to the 
social environment. But there was an indication that what might be considered mistakes on the part of producers are sometimes distinguished from damaging attitudes or practices. And the place of technology varied somewhat between product types, in one case combining with cultural and societal items but in the other cases also combining with producer-related items. This suggested that, in some cases, technology is seen as a given - part of the general background of society in which counterfeiting risks arise - but sometimes is seen as the responsibility of producers and can be part of the role they play in facilitating counterfeiting.

For the consequences, the factor structure separated out losses from benefits, although it separated consumer and public losses from producer losses, without separating consumer and producer benefits. The structures were similar for the three products, but producer price reductions sometimes associated mainly with benefits and sometimes (in the case of automotive parts) with losses. It is potentially an important message that certain kinds of risk, at least certain kinds of economic risk, can be seen as both harmful and beneficial, depending on the context. It is a reminder that risks are ultimately relational (Boholm and Corvellec, 2011) - only risky when relating to someone in a way that harms their interests (Garland, 2003).

\subsection{Control imperative judgments}

All regression models showed statistical significance but low or very low $R^{2}$ values. It is almost certain that the relationship between control imperative and the combination of causal judgments and risk size, although it is weak, is not a result of chance. But variation in control imperative does not arise primarily from judgments of how risks are caused or even how large in magnitude they are. Moreover, the roles of causation and size varied. As we discuss below, specific causal factors sometimes had significance when size did not, yet sometimes size had strong significance when specific causal factors did not. There is no single answer to the question whether the way a risk is caused is more or less important than the size of that risk in determining its control imperative. And it is reasonable to conclude that, although causation and size do have an influence in specific ways, 
people give counterfeiting risk a high control imperative largely because they find the act of counterfeiting inherently objectionable. Causation and size come second, supporting Wolff's (2006) argument that blameworthy risks can attract more concern than large-scale risks, and supporting Sjöberg's (2000) emphasis on the importance of morality in risk perception.

This is also supported by the way the potential benefits of counterfeiting to the legitimate economy, which would probably be regarded as controversial in any case, played no role in variations in control imperative. Although the principal components analysis revealed a factor we labelled 'consumer and producer benefit' for all three product types, this factor had no statistical significance in any of the regressions. Thus counterfeiting was not regarded as a risk that is traded off against some countervailing benefit.

The purpose of the qualitative comparative analysis was to find out what inhibited control imperative in the relatively small number of cases in which it was judged to be low. Simple propositional logic provided a natural way of expressing the idea that if we find control imperative to be low then we can infer that there is risk bearer causation: that the actors causing the risk are also the risk bearers - either because we think risk bearers should be the risk causers, or because we think risk causers should also be risk bearers. The results of the analysis bore this out. Control imperative was only inhibited when risk bearer causation was high (although it was high when risk bearer causation was both high and low).

\subsection{The nature of the goods}

The analysis suggested that the type of products makes a difference to the role that the causal factors and size of risk play. All three goods are safety critical in the sense that if they are manufactured in the wrong way they can kill those who consume them. This risk has probably materialised in all three cases, and in all three cases it is readily imaginable without expert knowledge. But alcohol is not, 
generally speaking, regarded as a healthcare product and consumption of alcohol is associated with risk to health, even when genuine. Automotive components are not products specifically intended to enhance health, but they are not inherently harmful if manufactured correctly. Pharmaceuticals are intended to enhance health so, when harmful, their effects are particularly at odds with expectations.

The fact that, for alcohol, the size of risk was only weakly predictive of the control imperative (in the causal model) and not predictive at all (in the consequential model) is understandable, given that consuming genuine alcohol is itself risky. For pharmaceuticals and automotive components the size of risk is more predictive of control imperative in both models because the consumption of genuine goods should not carry appreciable risk. It is interesting that Sjöberg (1999) found in two empirical studies that perceptions of the size of risk tended to be associated with probability, whereas the demand for risk reduction was associated with consequence. This apparent dissociation of risk size and control imperative is significant. Our results suggest that it is context sensitive: that, at least in the case of risks arising from counterfeiting, size is sometimes predictive of control imperative and sometimes not. They also suggest that the role of causation is context sensitive, generally important in some contexts but not in others. Context also selects particular causal factors for significance. The one constant across all three products was the consistency of the results with the proposition that diminished control imperative implies risk bearer causation.

\section{CONCLUSION}

The aim of the study was to understand certain aspects of how the risks presented by product counterfeiting are perceived. It is a risk that is very characteristic of modernity: a risk that arises because, in modern production systems, consumers must rely on trademarks and other kinds of signalling devices due to the fundamental knowledge asymmetry between themselves and producers (Ramello, 2006). They cannot know enough technical information about a pharmaceutical, for example, and about pharmacology in general, to assess its safety in any fundamental way. They have 
to rely on its trademark. When the trademark is fraudulently copied, a considerable risk is created. Counterfeiting is therefore a fundamental threat in a modern society, and counterfeiting risk an important risk to understand in its own right.

Our account of how people perceive this risk has been specifically concerned with the role of perceived causation. This was motivated by the heavy emphasis in the literature on the endogeneity of the causes of counterfeiting, and the ambiguous status of some of the consequences. The practices of a legitimate producer, including market segmentation, differential pricing, heavy advertising, restrictive distribution and so on probably encourage the production of counterfeits, for example. We were interested in how much influence individuals’ perceptions of causation had, relative to their perception of how big the risks were, when they made judgments about control imperative. Perhaps surprisingly we found that judged causation played only a small role. And with some kinds of product even the size of the risk played little obvious role. The situation varied across different product types, and for all product types the data was strongly consistent with the idea that what can make risks acceptable is that the agent of a risk is also a risk bearer.

For risk managers, it would be hard to justify not paying attention to risks associated with a phenomenon like the counterfeiting of safety critical products. Yet the attention paid to such risks still has to be rationed. The message from this study appears to be that it cannot be rationed on the basis of some risk-benefit balance because individuals see little (although non-zero) benefit to legitimate actors from counterfeiting. But, equally, it cannot be rationed on the basis that those who bear the risks are also, to some degree, agents of their own misfortune. Even when this is true, it has only a minor effect on the acceptability of those risks.

Our intended contributions are these:

- To have explored risk perceptions in relation to the important risk issue of product counterfeiting, an issue that, in terms of intentionality, occupies a middle ground between accidents (in which 
there is characteristically no wrongful intention) and terrorism (in which the intention is to cause harm).

- To have explored risk perceptions in Chinese society: a society in which the counterfeiting risk is often thought of as being endemic, in which consumers and producers are sometimes regarded as being ambivalent about the counterfeiting phenomenon, and one that now constitutes the world's second largest economy.

- To have explored the perception of causation, specifically, analysing how far this influences the risk control imperative.

The most obvious limitation of the work is the use of a convenience sample, suggesting the need to replicate the study with a nationally representative sample of respondents. But the study also relied on the literature on counterfeiting to generate the items to which individuals responded, and there is a need for a more open-ended investigation of how people attribute causation for risks such as counterfeiting whose risks are complex and involve agents acting with intention but not the intention to cause physical harm. There is also a need to explain the variance that causation and size of risk failed to explain in this study - perhaps to follow Sjöberg (2000) and take account of individuals' risk sensitivity and their attitude (in this case, especially their attitude to criminality). There is also a question about the significance of individuals' risk perceptions, and especially the average of those perceptions, in a society that is experiencing rapid and uneven economic growth. Is the relatively weak relationship between the causes of counterfeiting risk and control imperative something that allows risk managers in the legitimate economy not to worry unduly about trying to control this risk?

\section{REFERENCES}

Aryanto, V.D.W. (2003). Intellectual property rights theft in far east countries. Journal of Business Administration Online, 2, 2, [pages unnumbered]. 
Boholm, A. and Corvellec, H. (2011). A relational theory of risk. Journal of Risk Research, 14, 175190.

Bosworth, D. (2006). Counterfeiting and piracy: The state of the art. Intellectual Property in the New Millennium Seminar, Oxford, (9 $9^{\text {th }}$ May 2006).

Bronfman, N. and Cifuentes, L.A. (2003). Risk perception in a developing country: the case of Chile. Risk Analysis, 23, 1309-1323.

Busby, J.S. (2008). Analysing complicity in risk. Risk Analysis, 28, 1571-1582.

Busby, J.S. and Duckett, D. (2012): Social risk amplification as an attribution: the case of zoonotic disease outbreaks. Journal of Risk Research, 15, 1049-1074.

Cai, S., Jun, M., and Yang, Z. (2010). Implementing supply chain information integration in China: The role of institutional forces and trust, Journal of Operations Management, 28, 257-268.

Caponecchia, C. (2012). Relative risk perception for terrorism: implications for preparedness and risk communication. Risk Analysis, 32, 1524-1534.

Carver, A. (1996). Open and secret regulations in China and their implication for foreign investment, in Child, J. and Lu, Y. (Eds), Management Issues in China: International Enterprises, Routledge (London, UK).

Chan, A., Wong, S. and Leung, P. (1998). Ethical beliefs of Chinese consumers in Hong Kong. Journal of Business Ethics, 17, 1163-1170.

Chaudhry, P.E. and Walsh, M.G. (1996). An assessment of the impact of counterfeiting in international markets: The piracy paradox persists. The Columbia Journal of World Business, 31, $34-47$.

Cordell, V.V., Wongtada, and Kieschnick, R.L. (1996). Counterfeit purchase intentions: Role of lawfulness attitudes and product traits as determinants. Journal of Business Research, 35, 41-53.

Dixon, P. and Greenhalgh, C. (2002). The economics of intellectual property: A review to identify themes for future research, University of Oxford Department of Economics Discussion Paper Series, No. 135 (accessed at http://www.economics.ox.ac.uk/Research/wp/pdf/paper135.pdf on 7th January 2011). 
Dohle, S., Keller, C. and Siegrist, M. (2010). Examining the relationship between affect and implicit associations: implications for risk perception. Risk Analysis, 30, 1116-1128.

Eisend, M. and Schuchert-Güler, P. (2006). Explaining counterfeit purchases: A review and preview. Academy of Marketing Science Review, 10, (no page numbers).

FDA (2004). Combating counterfeit drugs: a report of the Food and Drug Administration, US Department of Health and Human Services, Food and Drug Administration, Rockville, MD, February.

Feinberg, R.M. and Rousslang, D.J. (1990). The economic effects of intellectual property right infringements. Journal of Business, 63, 79-90.

Finkel, A.M. (2008). Perceiving others’ perceptions of risk: still a task for Sisyphus. Ann. N.Y. Acad. Sci., 1125, 121-137.

Finucane, M.L., Alhakami, A., Slovic, P. and Johnson, S.M. (2000). The affect heuristic in judgments of risks and benefits. Journal of Behavioral Decision Making, 13, 1-17.

Fischhoff, B., Slovic, P., Lichtenstein, S., Read, S. and Combs, B. (1978). How safe is safe enough? A psychometric study of attitudes towards technological risks and benefits. Policy Sciences, 9, 127152.

Forzley, M. (2003). Counterfeit goods and the public's health and safety. International Intellectual Property Institute, Washington.

Freudenberg WR (2003). Institutional failure and the organizational amplification of risk: The need for a closer look. In: Pidgeon N, Kasperson RE and Slovic P (eds). The Social Amplification of Risk. Cambridge University Press: Cambridge, UK, pp 102-120.

Garland, D. (2003). The rise of risk. In Ericson, R.V. and Doyle, A. (Eds.), Risk and Morality, University of Toronto Press (Toronto), pp. 48-86.

Gillette, F. (2013). Inside Pfizer’s fight against counterfeit drugs. Bloomberg Business Week, http://www.businessweek.com/articles/2013-01-17/inside-pfizers-fight-against-counterfeit-drugs, posted January $13^{\text {th }}$.

Green, R.T. and Smith, T. (2002). Executive insights: Countering brand counterfeiters. Journal of International Marketing, 10, 89-106. 
Grossman, G.M. and Shapiro, C. (1988a). Counterfeit-product trade. American Economic Review, 78, 59-75.

Grossman, G.M. and Shapiro, C. (1988b). Foreign counterfeiting of status goods, Quarterly Journal of Economics, 103, 79-100.

Guide, V.D.R., Jayaraman, V., and Linton, J.D. (2003). Building contingency planning for closed-loop supply chains with product recovery, Journal of Operations Management, 21, 259-279.

Hilgartner, S. The social construction of risk objects: Or, how to pry open networks of risk. In Short, J.F. and Clarke, L. (Eds.) (1992). Organizations, Uncertainties, and Risk. Westview Press (Boulder, CO), pp. 39-53.

Hilton, B., Choi, C.J. and Chen, S. (2004). The ethics of counterfeiting in the fashion industry: Quality, credence and profit issues, Journal of Business Ethics, 55, 345-354, 2004.

Hornig Priest, S. (2012). Nanotechnology and the Public: Risk Perception and Risk Communication. CRC Press (Boca Raton).

IACC (2005). The negative consequences of international intellectual property theft: economic harm, threats to the public health and safety, and links to organized crime and terrorist organizations. White Paper, January, International Anti-Counterfeiting Coalition, Washington, DC, available at: www.iacc.org (accessed 8 March 2011).

Kochen, M. (1975). Applications of fuzzy sets in psychology. In Zadeh, L.A., Fu, K.-S., Tanaka, K. and Shimura, M. (eds.), Fuzzy Sets and Their Applications to Cognitive and Decision Processes. Academic Press (New York), pp. 395-408.

Jiang, B., Frazier, G.V., and Heiser, D. (2007). China-related POM research: A literature review and suggestions for future research, International Journal of Operations and Production Management, 27, 7, 662-684.

Juillet, Y. and Vlasto, A.-P. (2005). Counterfeiting of medicinal drugs: issues and threats. Fundamental and Clinical Pharmacology, 19, 621-624.

Kellens, W., Zaalberg, R., Neutens, T., Vanneuville, W. and De Maeyer, P. (2011). An analysis of the public perception of flood risk on the Belgian coast. Risk Analysis, 31, 1055-1068.

Kuhar, S.E., Nierenberg, K., Kirkpatrick, B. and Tobin, G.A. (2009). Public perceptions of Florida red 
tide risks. Risk Analysis, 29, 963-969.

Langford, I.H., Marris, C., McDonald, A.-L., Goldstein, H., Rasbash, J. and O’Riordan, T. (1999).

Simultaneous analysis of individual and aggregate responses in psychometric data using multilevel modeling. Risk Analysis, 19, 675-683.

Lee, J.E.C. and Lemyre, L. (2009). A social-cognitive perspective of terrorism risk perception and individual response in Canada. Risk Analysis, 29, 1265-1280.

Lister, S. (2006), “Heart patients get fake drugs supplied to NHS pharmacies”, 3 August 2006, available at: www.timesonline.co.uk/tol/news/uk/health/article698376.ece, (accessed 28 July 2010)

Luedeman, R.W. (1997). Flying underground: The trade in bootleg aircraft parts, Journal of Air Law and Commerce, 62, 93-160.

Mackenzie, S. (2010). Counterfeiting as corporate externality: Intellectual property crime and global insecurity, Crime Law Soc Change, 54, 21-38.

Mandhachitara, R., Smith, T. and Blois, K. (2000). Thailand's counterfeit dilemma, Proceedings of Australian and New Zealand Marketing Academy Conference (ANZMAC), Queensland, $28^{\text {th }}$ November- $1^{\text {st }}$ December.

Marris, C., Langford, I., Saunderson, T. and O’Riordan, T. (1997). Exploring the “psychometric paradigm”: comparisons between aggregate and individual analyses. Risk Analysis, 17, 303-312.

Marucheck, A., Greis, N., Mena, C., and Cai, L. (2011b). Editorial essay: Product safety and security in the global supply chain: Issues, challenges and research opportunities, Journal of Operations Management, 29, 707-720.

Mavlanova, T.and Benbunan-Fich, R. (2010). Counterfeit products on the Internet: the role of sellerlevel and product-level information. International Journal of Electronic Commerce, 15, 79-104.

Merz, T. (2013). Apple to replace counterfeit chargers following electrocution. The Telegraph, http://www.telegraph.co.uk/technology/news/10225969/Apple-to-replace-counterfeit-chargersfollowing-electrocution.html, posted August $6^{\text {th }}$.

Minagawa, T.J., Trott, P., and Hoecht, A. (2007). Counterfeit, imitation, reverse engineering and learning: Reflections from Chinese manufacturing firms, RandD Management, 37, 455-467. 
Ming, W.X., and Xing, Z. (2000). A new strategy of technology transfer to China, International Journal of Operations and Production Management, 19, 5-6, 527-537.

Mittlestaedt, J.D. and Mittlestaedt, R.A. (1997). The protection of intellectual property: Issues of origination and ownership. Journal of Public Policy and Marketing, 16, 14-25.

Newton, P.N., Green, M.D., Fernández, F.M., Day, N.P.J. and White, N.J. (2006). Counterfeit antiinfective drugs, Lancet Infect Diseases, 6, 602-13.

Prati, G., Pietrantoni, L. and Zani. B. (2011). A social-cognitive model of pandemic influenza H1N1 risk perception and recommended behaviors in Italy. Risk Analysis, 31, 645-656.

Qian, Y. (2008). Impacts of entry by counterfeiters, Quarterly Journal of Economics, 123, 1577-1609.

Ragin, C.C. (2000). Fuzzy-Set Social Science. University of Chicago Press (Chicago).

Ragin, C. (2006). Set relations in social research: evaluating their consistency and coverage. Political Analysis, 14, 291-310.

Ragin, C. (2009). Qualitative comparative analysis using fuzzy sets (fsQCA). In Rihoux, B. and Ragin, C. (eds.), Configurational Comparative Methods: Qualitative Comparative Analysis (QCA) and Related Techniques. Sage (Thousand Oaks), pp. 87-122.

Rihoux, B. (2006). Qualitative comparative analysis (QCA) and related systematic comparative methods: recent advances and remaining challenges for social science research. International Sociology, 21, 679-706.

Ramello, G.B. (2006). What's in a sign? Trademark law and economic theory, Journal of Economic Surveys, 20, 547-565.

Rutter, J. and Bryce, J. (2008). The consumption of counterfeit goods: 'Here be pirates?', Sociology, 42, 1146-1164.

Sandman, P.M., Miller, P.M., Johnson, B.B., Weinstein, N.D. (1993). Agency communication, community outrage, and perception of risk: three simulation experiments. Risk Analysis, 13, 585598.

Santos, J.F. and Ribeiro, J.C. (2007). International counterfeiting in the European Union: A host country approach. Journal of Euromarketing, 16, 165-176.

Seawright, J. (2005). Qualitative comparative analysis vis-à-vis regression. Studies in Comparative 
International Development, 40, 3-26.

Shen, A., Antonopoulos, G.A. and Von Lampe, K. (2010). The dragon breathes smoke: cigarette counterfeiting in the People’s Republic of China, British Journal of Criminology, 50, 239-258.

Shultz, C.J., and Saporito, B. (1996). Protecting intellectual property: Strategies and recommendations to deter counterfeiting and brand piracy in international markets, Columbia Journal of World Business 31, 18-28.

Siegrist, M., Keller, C. and Kiers, H.A.L. (2005). A new look at the psychometric paradigm of perception of hazards. Risk Analysis, 25, 211-222.

Siegrist, M., Keller, C., Kastenholz, H., Frey, S. and Wiek, A. (2007). Laypeople’s and experts' perception of nanotechnology hazards. Risk Analysis, 27, 59-69.

Sjöberg, L. (1996). A discussion of the limitations of the psychometric and cultural theory approaches to risk perception. Radiation Protection Dosimetry, 68, 219-225.

Sjöberg, L. (1999). Consequences of perceived risk: demand for mitigation. Journal of Risk Research, 2, 129-149.

Sjöberg, L. (2000). Factors in risk perception. Risk Analysis, 20, 1-11.

Slovic, P., Fischhoff, B. and Lichtenstein, S. (1982). Why study risk perception? Risk Analysis, 2, 8393.

Slovic, P., Finucane, M.L., Peters, E. and MacGregor, D. (2004). Risk as analysis and risk as feelings: some thoughts about affect, reason, risk, and rationality. Risk Analysis, 24, 311-322.

Staake, T., Thiesse, F., and Fleisch, E. (2009). The emergence of counterfeit trade: A literature review, European Journal of Marketing, 43, 320-349.

Tom, G., Garibaldi, B., Zeng, Y. and Pilcher, J. (1998). Consumer demand for counterfeit goods, Psychology and Marketing, 15, 405-421.

Trott, P. and Hoecht, A. (2007). Product counterfeiting, non-consensual acquisition of technology and new product development: An innovation perspective. European Journal of Innovation Management, 10, 126-143.

Vagg, J. And Harris, J. (2000). False profits: why product counterfeiting is increasing. European Journal on Criminal Policy and Research, 8, 107-115. 
Veloutsou, C. and Bian, X. (2008). A cross-national examination of consumer perceived risk in the context of non-deceptive counterfeit brands. Journal of Consumer Behavior, 7, 3-20.

Villasenor, J. and Tehranipoor, M. (2013). The hidden dangers of chop-shop electronics. IEEE Spectrum, http://spectrum.ieee.org/semiconductors/processors/the-hidden-dangers-of-chopshopelectronics/?utm_source=techalertandutm_medium=emailandutm_campaign=100313, posted September $20^{\text {th }}$.

Wilke, R. (1999), Brand imitation and its effects on innovation, competition, and brand equity, Business Horizons, 42, 9-18.

Wolff, J. (2006). Risk, fear, blame, shame and the regulation of public safety. Economics and Philosophy, 22, 409-427.

WTO (2013). Glossary. http://www.wto.org/english/thewto_e/glossary_e/glossary_e.htm. Accessed on October 14th.

Yar, M. (2005). A deadly faith in fakes: Trademark theft in counterfeit automotive components, Internet Journal of Criminology, 1-33.

Yar, M. (2008). The other global drugs crisis: Assessing the scope, impacts and drivers of the trade in dangerous counterfeit pharmaceuticals, International Journal of Social Inquiry, 1, 151-166.

Yen, J. and Langari, R. (1999). Fuzzy Logic: Intelligence, Control, and Automation. Prentice Hall (Upper Saddle River, NJ). 


\section{APPENDIX}

The following schedule of items was presented separately for each product type (alcoholic beverages, pharmaceuticals and automotive components) indicated as $[\mathrm{x}]$. The administered questionnaire was translated to Chinese:

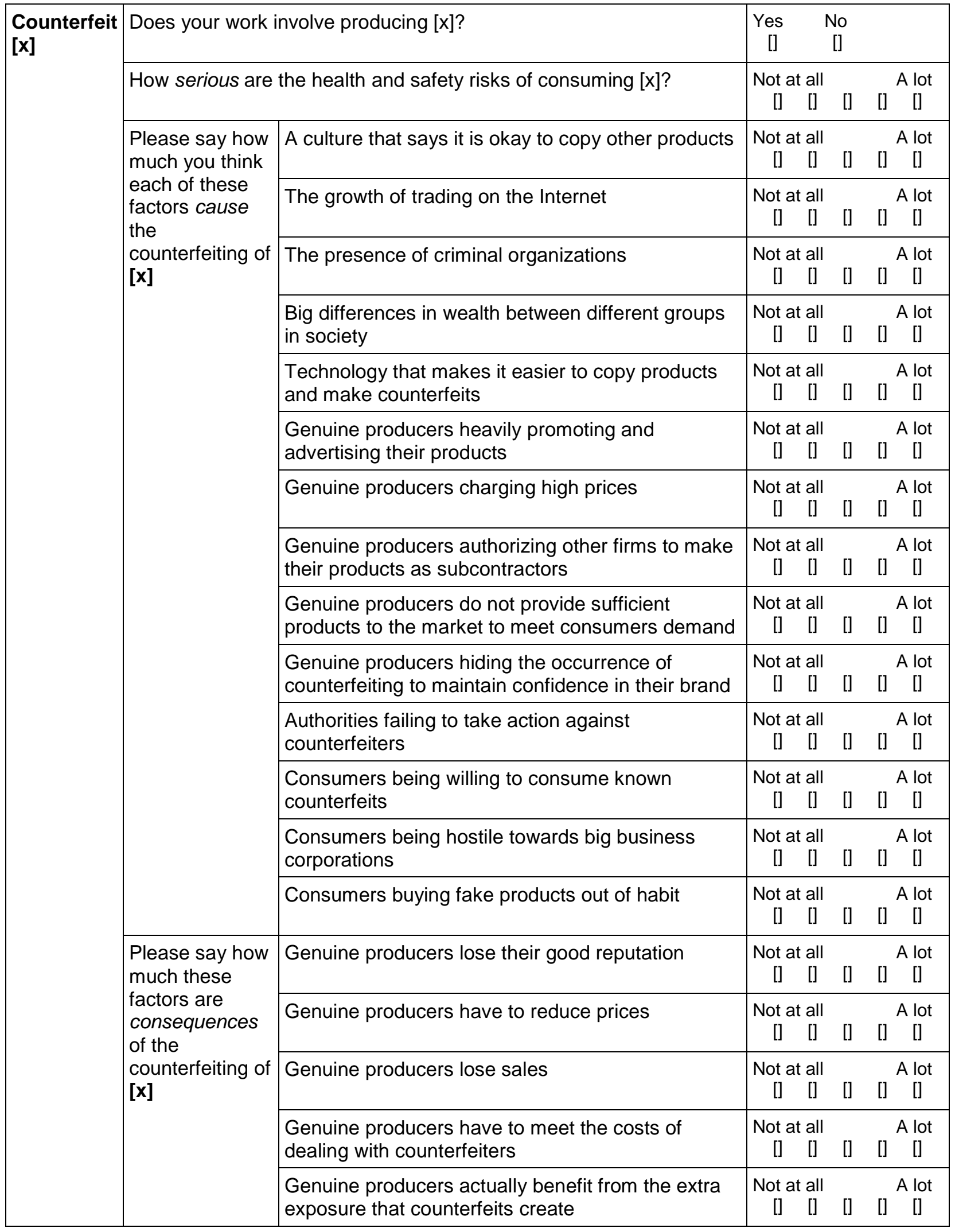




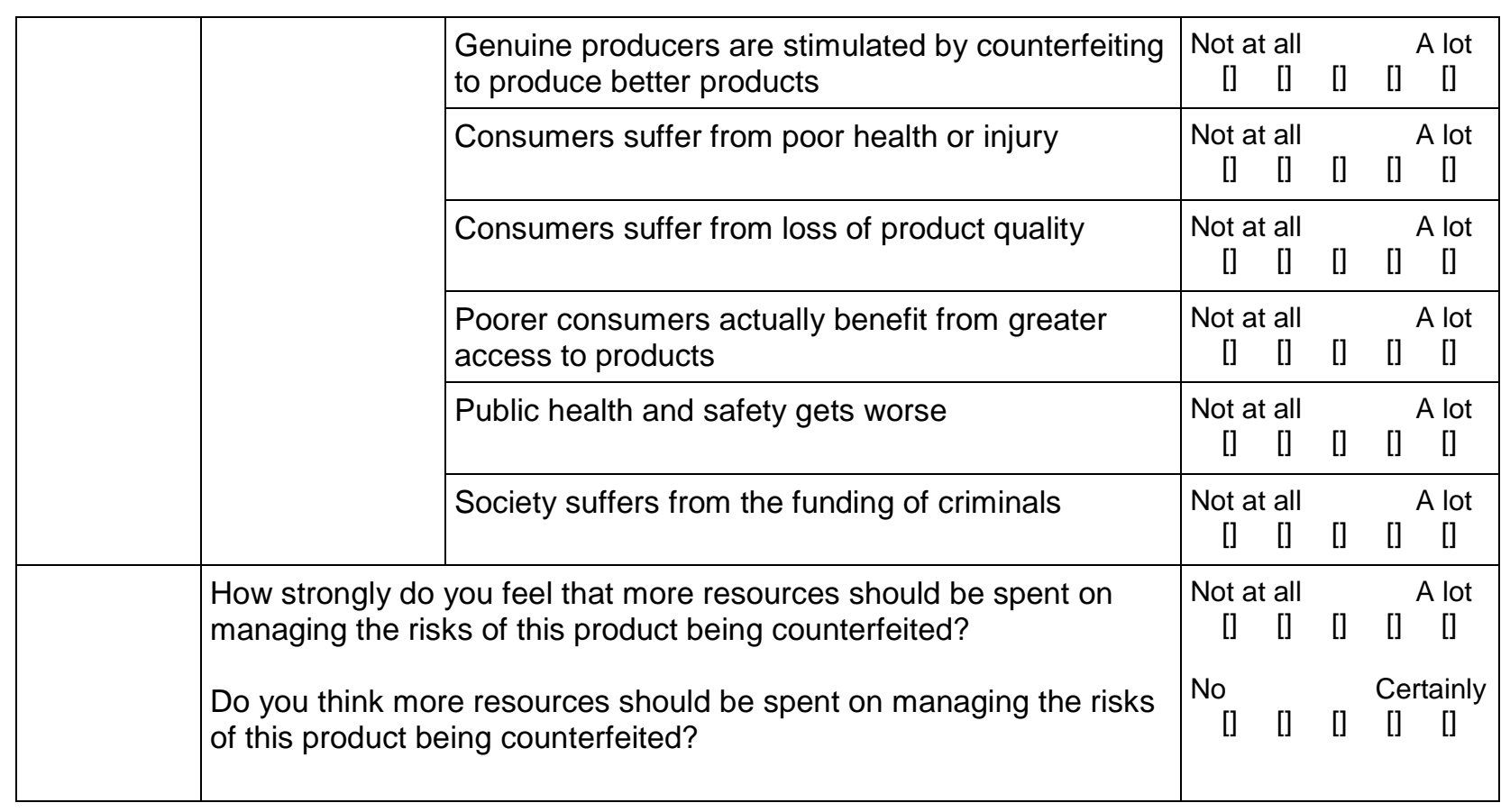


Figure 1: The main causation around counterfeiting identified in the literature

Causes exogenous to producers and consumers:

Culture tolerating intellectual property rights violation

Authorities failing to act

Large disparities in wealth between groups

(Removal of trade barriers and restrictions)

Presence of criminal organizations

High-fidelity reproduction technology facilitating copying

Growth of Internet trading

(Cost and transience of anti-counterfeiting technology)
Causes endogenous to consumers: Willingness to consume known counterfeits

(Attitudes of lawlessness)

Hostility towards 'big business'

Habituation to consuming counterfeits

\section{Causes endogenous to producers:}

Heavy promotion of products

Profiteering

(Market segmentation and differential pricing)

Outsourcing and licensing production

Failing to meet demand eg by stopping production

Hiding the incidence of counterfeiting

Consequences for producers:

Reputational loss

Price falls

Revenue loss

Cost of prevention and mitigation

Additional market exposure

Stimulus to produce at higher quality

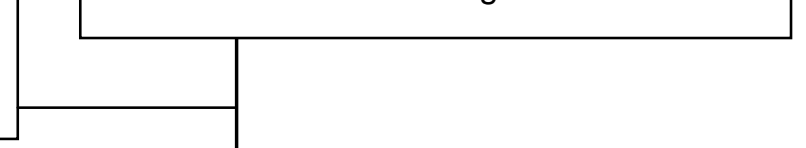

$\checkmark$

\section{Counterfeiting activity}


Figure 2: Distributions of age, self-perceived wealth, employment and education for the respondent sample

\section{Age}

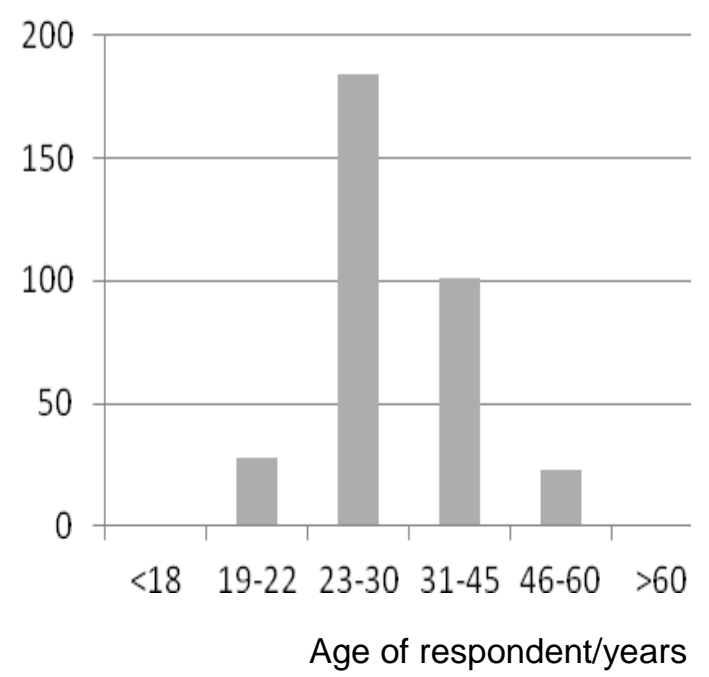

Employment

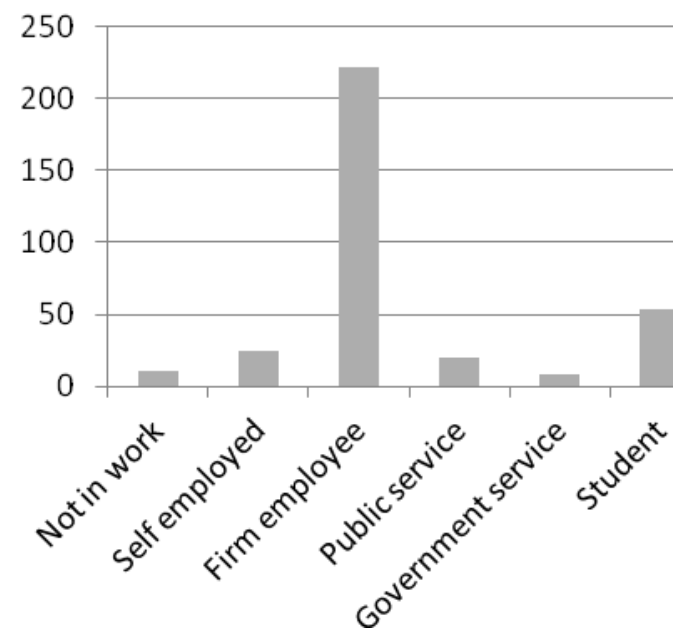

Employment type
Wealth

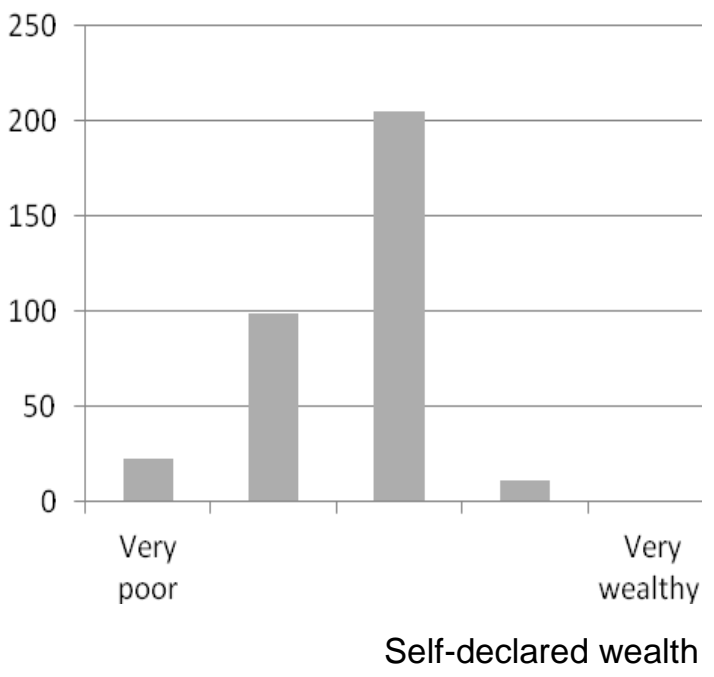

Education

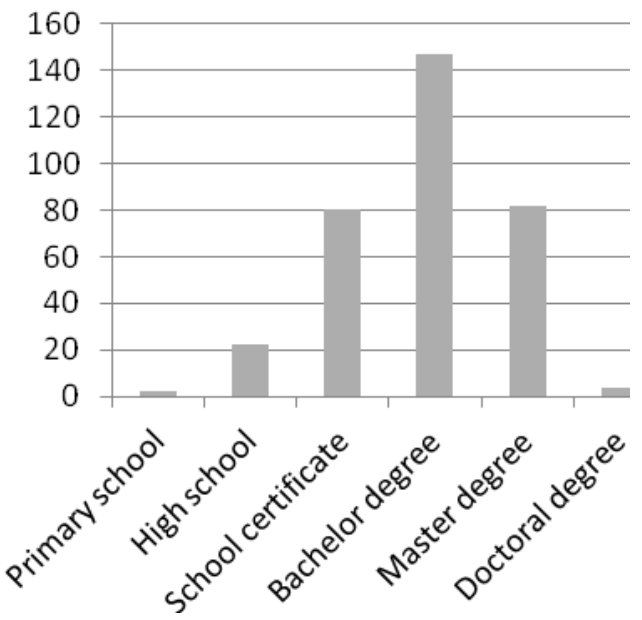

Highest level of education type 
Figure 3: Mean responses plus or minus one standard deviation for all causes for the three product types

Alcoholic beverages

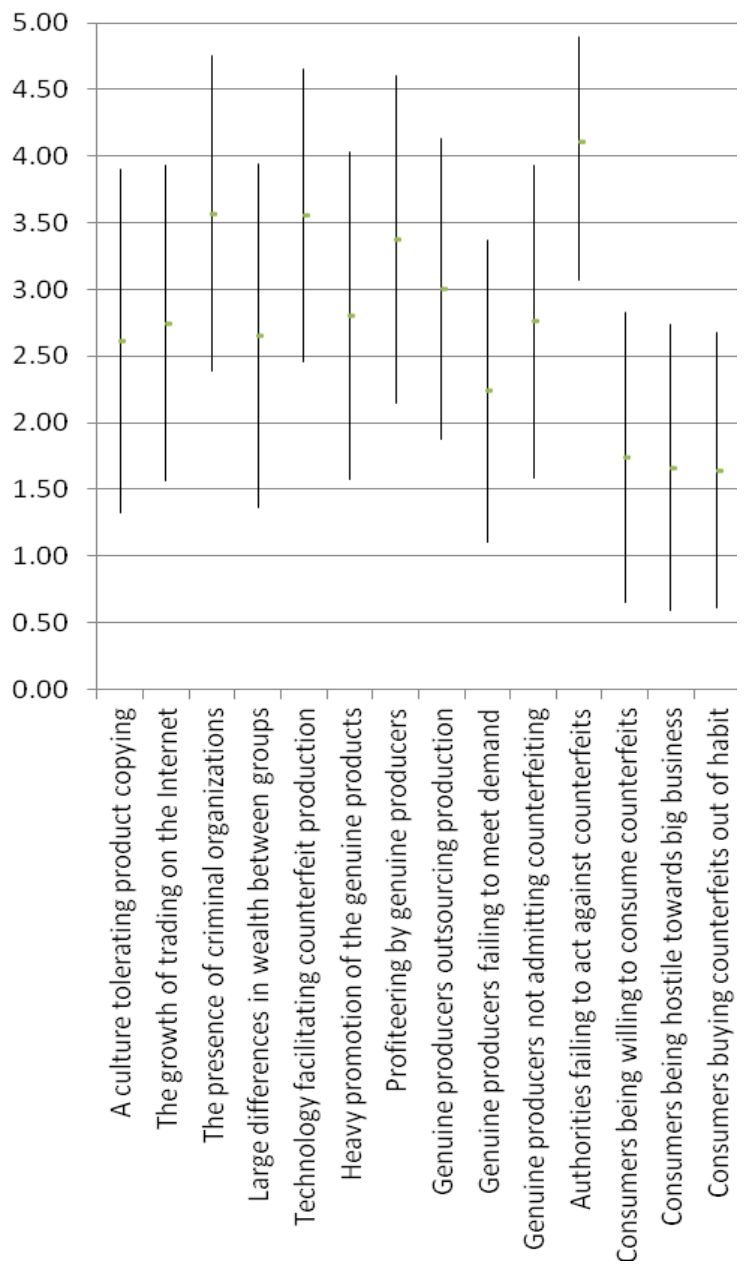

Pharmaceuticals

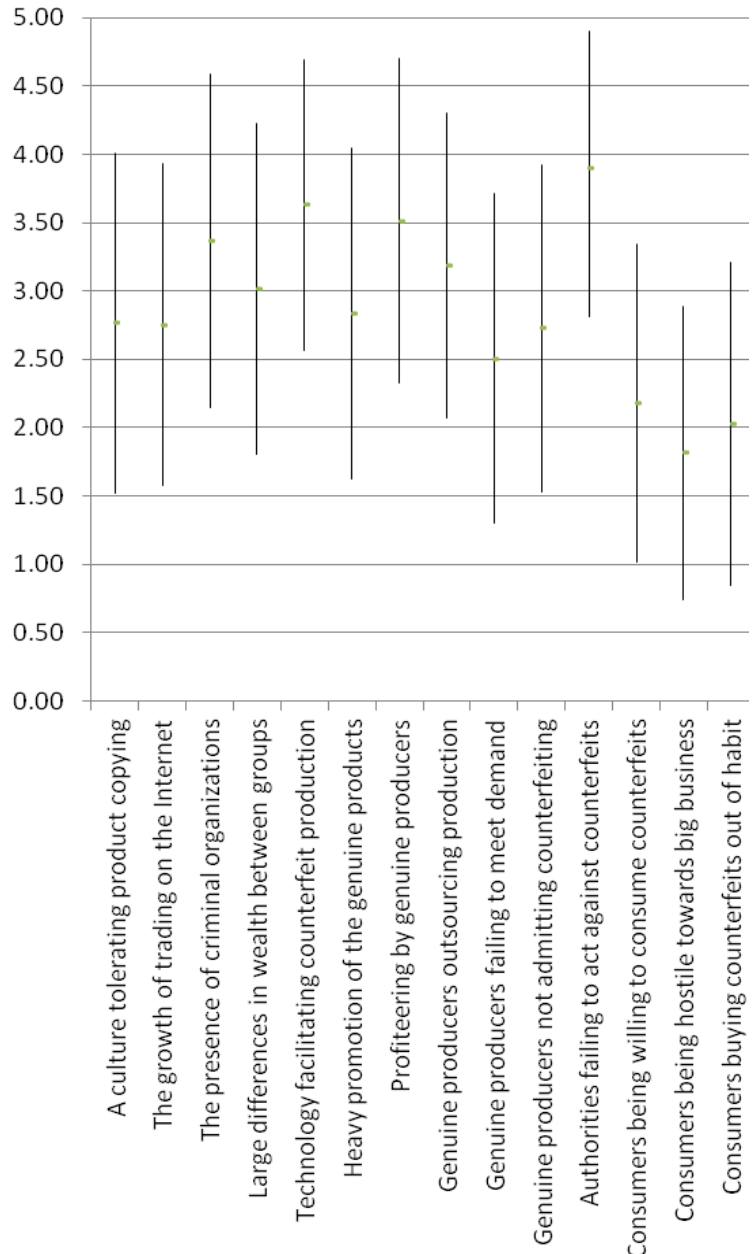

Automotive parts

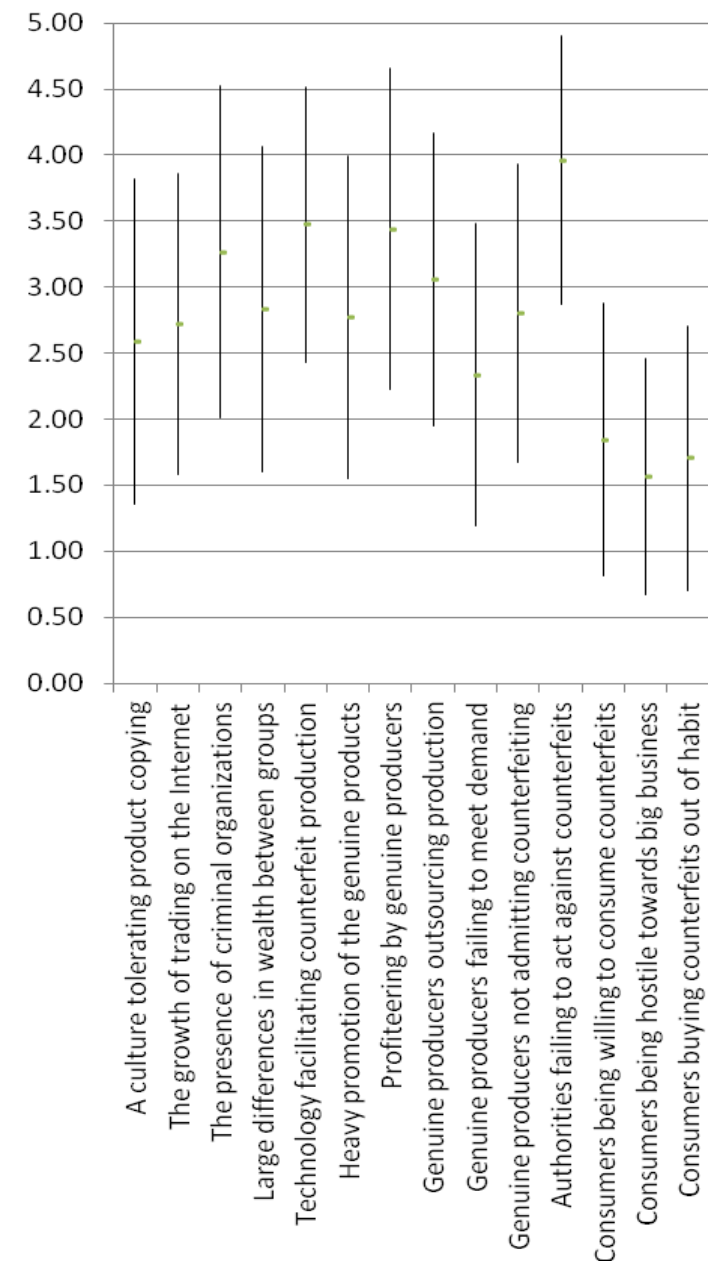


Figure 4: Mean responses plus or minus one standard deviation for all consequences for the three product types
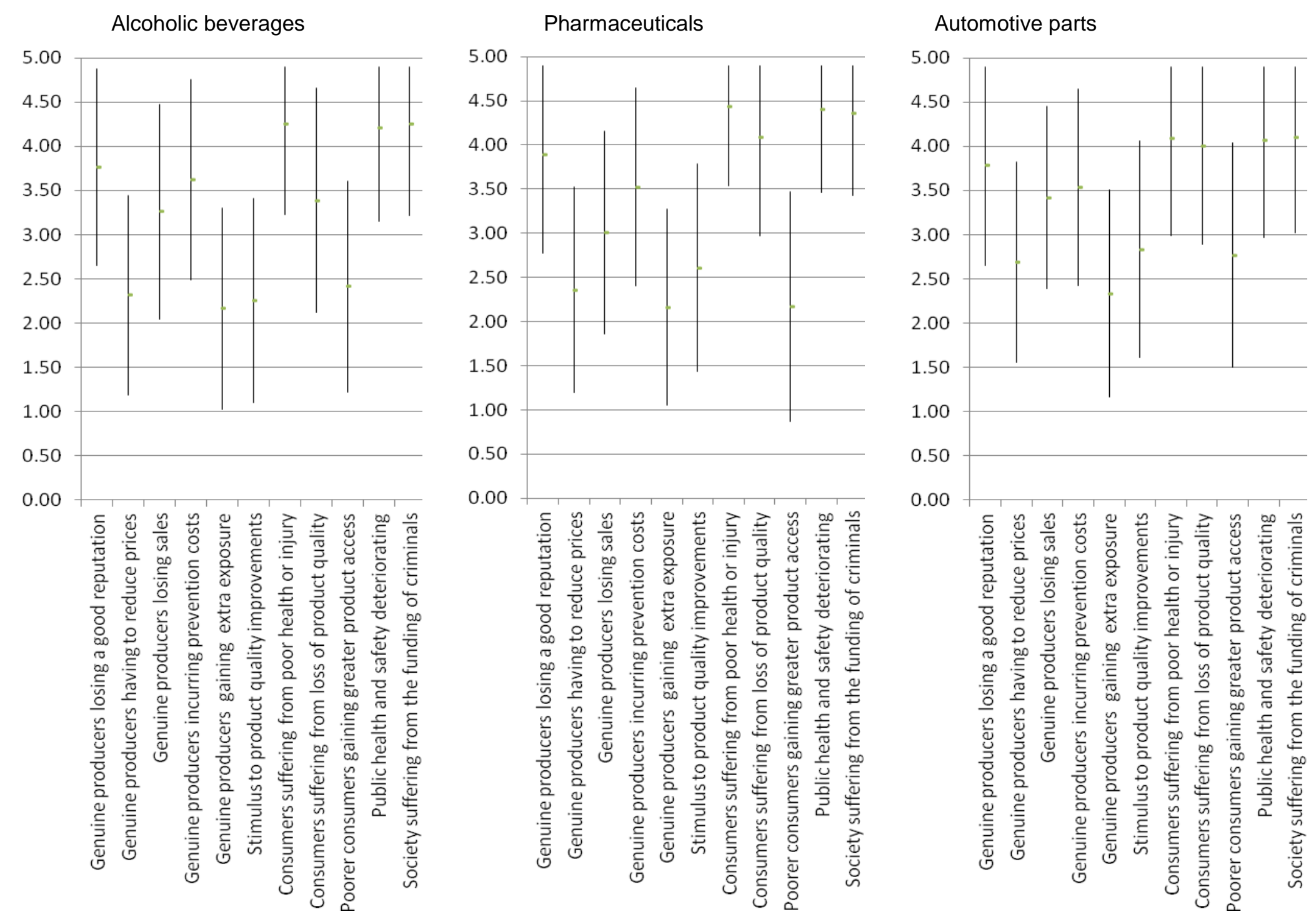
Table 1: Factor structures for causes

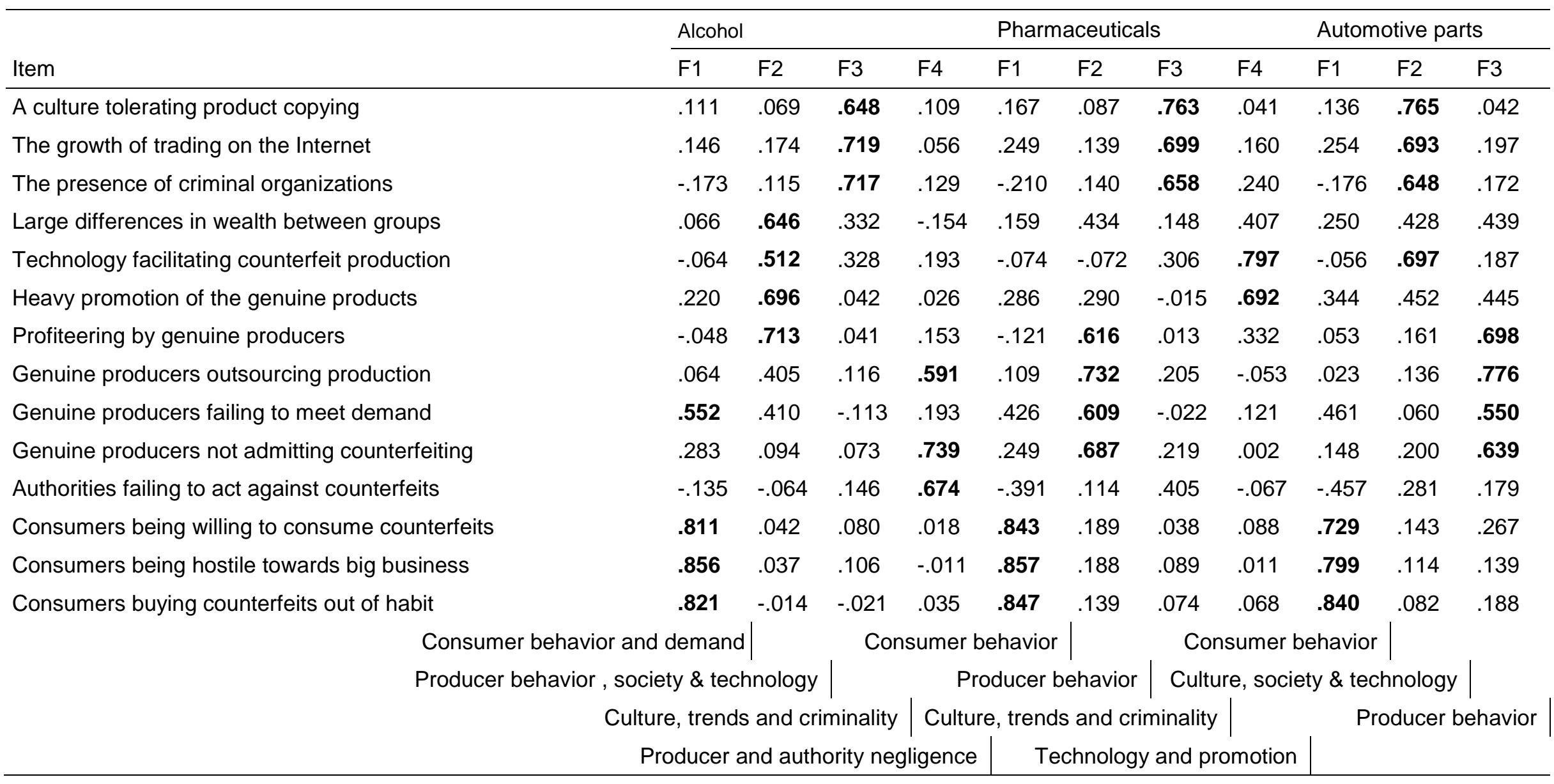


Table 2: Factor structures for consequences

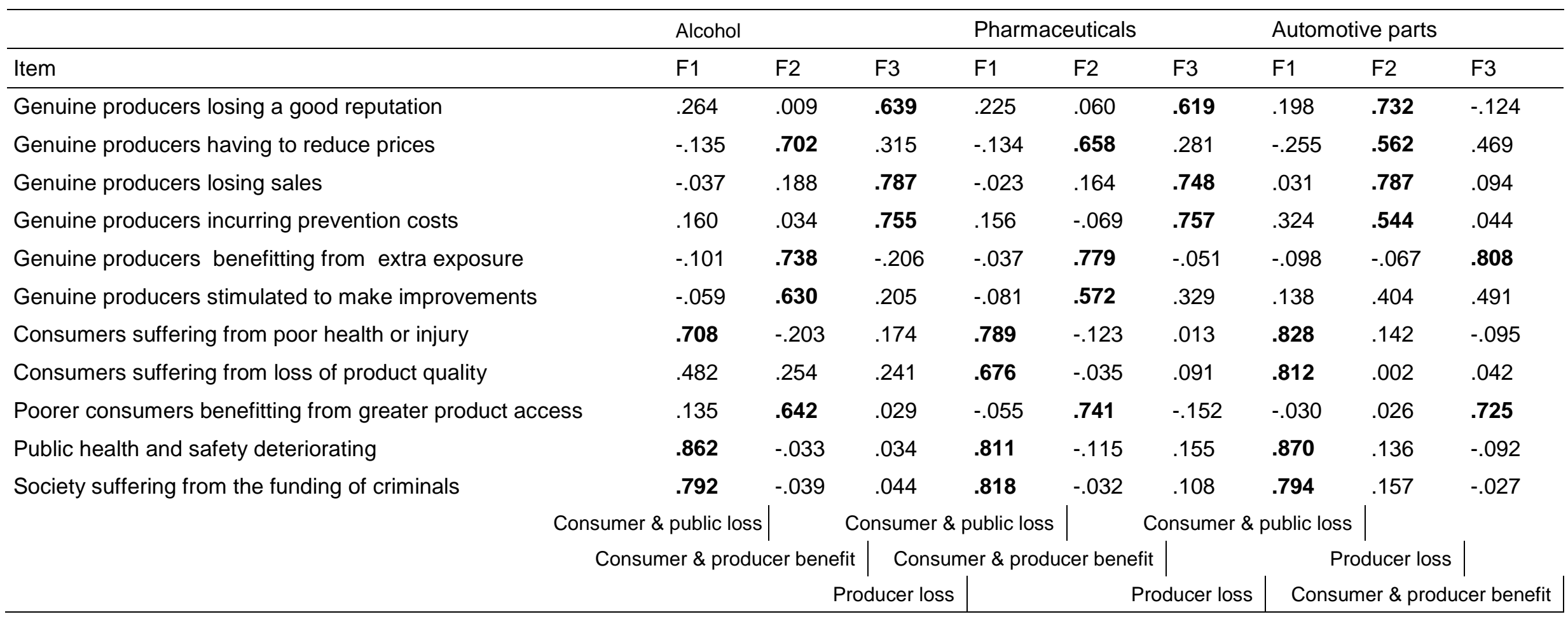


Table 3: Risk control imperative explained by causal factors and scale of risk

\begin{tabular}{|c|c|c|c|c|c|c|}
\hline & \multicolumn{2}{|l|}{ Alcohol } & \multicolumn{2}{|c|}{ Pharmaceuticals } & \multicolumn{2}{|c|}{ Automotive parts } \\
\hline Adjusted $R^{2}$ & .043 & & .143 & & .165 & \\
\hline ANOVA model significance & .002 & & .000 & & .000 & \\
\hline Coefficients & $\begin{array}{l}\text { Unstd. } \\
\text { value }\end{array}$ & $\begin{array}{l}\text { Signif. } \\
\text { level }\end{array}$ & $\begin{array}{l}\text { Unstd. } \\
\text { value }\end{array}$ & $\begin{array}{l}\text { Signif. } \\
\text { level }\end{array}$ & $\begin{array}{l}\text { Unstd. } \\
\text { value }\end{array}$ & $\begin{array}{l}\text { Signif. } \\
\text { level }\end{array}$ \\
\hline (Intercept) & 3.245 & $.000^{* *}$ & 2.767 & $.000^{\star *}$ & 2.413 & $.000^{\star \star}$ \\
\hline Scale of risk & .185 & $.011^{\star}$ & .351 & $.000^{\star \star}$ & .409 & $.000^{\star \star}$ \\
\hline $\begin{array}{l}\text { Consumer behavior and } \\
\text { demand }\end{array}$ & -.122 & $.021^{*}$ & & & & \\
\hline $\begin{array}{l}\text { Producer behavior, society } \\
\text { and technology }\end{array}$ & .039 & .460 & & & & \\
\hline $\begin{array}{l}\text { Culture, trends and } \\
\text { criminality }\end{array}$ & .071 & .182 & & & & \\
\hline $\begin{array}{l}\text { Producer and authority } \\
\text { negligence }\end{array}$ & .093 & .080 & & & & \\
\hline Consumer behavior & & & -.199 & $.000 * \star$ & & \\
\hline Producer behavior & & & -.058 & .219 & & \\
\hline $\begin{array}{l}\text { Culture, trends and } \\
\text { criminality }\end{array}$ & & & .139 & $.004^{\star \star}$ & & \\
\hline $\begin{array}{l}\text { Technology and producer } \\
\text { promotion }\end{array}$ & & & .125 & $.009^{\star \star}$ & & \\
\hline Consumer behavior & & & & & -.082 & .080 \\
\hline $\begin{array}{l}\text { Culture, society and } \\
\text { technology }\end{array}$ & & & & & .206 & $.000^{\star *}$ \\
\hline Producer behavior & & & & & -.021 & .642 \\
\hline
\end{tabular}

$* p<0.05 ; * * p<0.01$ 
Table 4: Control imperative explained by consequential factors and scale of risk

\begin{tabular}{|c|c|c|c|c|c|c|}
\hline & \multicolumn{2}{|l|}{ Alcohol } & \multicolumn{2}{|c|}{ Pharmaceuticals } & \multicolumn{2}{|c|}{ Automotive parts } \\
\hline Adjusted $R^{2}$ & .119 & & .158 & & .175 & \\
\hline ANOVA model significance & .000 & & .000 & & .000 & \\
\hline Coefficients & $\begin{array}{l}\text { Unstd. } \\
\text { value }\end{array}$ & $\begin{array}{l}\text { Signif. } \\
\text { level }\end{array}$ & $\begin{array}{l}\text { Unstd. } \\
\text { value }\end{array}$ & $\begin{array}{l}\text { Signif. } \\
\text { level }\end{array}$ & $\begin{array}{l}\text { Unstd. } \\
\text { value }\end{array}$ & $\begin{array}{l}\text { Signif. } \\
\text { level }\end{array}$ \\
\hline (Intercept) & 3.635 & $.000^{\star *}$ & 2.736 & $.000^{\star \star}$ & 2.815 & $.000^{* \star}$ \\
\hline Scale of risk & .098 & .183 & .358 & $.000^{\star \star}$ & .320 & $.000^{* \star}$ \\
\hline Consumer and public loss & .171 & $.001^{\star *}$ & .270 & $.000^{\star \star}$ & .252 & $.000^{* \star}$ \\
\hline $\begin{array}{l}\text { Consumer and producer } \\
\text { benefit }\end{array}$ & -.124 & $.015^{*}$ & -.084 & .078 & .047 & .303 \\
\hline Producer loss & .250 & $.000^{\star *}$ & .092 & .052 & -.016 & .734 \\
\hline
\end{tabular}

$* p<0.05 ;{ }^{* *} p<0.01$ 
Table 5: Consistency and coverage indices for the configurational analysis

\begin{tabular}{lllll}
\hline Product & $\begin{array}{l}\text { Consistency } \\
\text { Form (1) }\end{array}$ & Form (2) & $\begin{array}{l}\text { Coverage } \\
\text { Form (1) }\end{array}$ & Form (2) \\
\hline Alcohol & 0.997 & 0.958 & 0.243 & 0.285 \\
Pharmaceuticals & 0.995 & 0.973 & 0.140 & 0.180 \\
Automotive parts & 0.992 & 0.959 & 0.200 & 0.220 \\
\hline
\end{tabular}

